\title{
The significance of polymorphisms of gene coagulation factors VII and XIII in the pathogenesis of non-traumatic avascular necrosis of the femoral head
}

\author{
M.A. Panin ${ }^{1}$, N.V. Zagorodnii ${ }^{1}$, A.V. Boiko ${ }^{1}$, L.M. Samokhodskaya ${ }^{2}$, M.D. Abakirov ${ }^{1}$, E.E. Volkov ${ }^{3}$ \\ ${ }^{1}$ Peoples Friendship University of Russia, Moscow, Russian Federation \\ ${ }^{2}$ M.V.Lomonosov Moscow State University, Moscow, Russian Federation \\ ${ }^{3}$ Specialized Center for the Treatment of Aseptic Necrosis, Moscow, Russian Federation
}

\begin{abstract}
Introduction Non-traumatic avascular necrosis of the femoral head (ANFH) is a poly-etiologic and socially significant disease in the age of 20 to 50 years and is associated with disability. Research on the identification of necrosis causes/predictors is a relevant issue. Purpose To study the contribution of polymorphisms in the genes of coagulation factors F7 and F13 in the aetiology of non-traumatic avascular necrosis of the femoral head. Methods Polymorphisms of the genes of coagulation factors F7 and F13 were studied; comparative analysis of the frequency of important allelic variants of F7genes (Arg353Gln) and F13 (Val134Leu) in patients with a verified diagnosis of aseptic necrosis (study group) and in healthy patients (control group) was performed. The study group included 41 patients (all males) with aseptic necrosis of the femoral head of unknown etiology. Results The frequency of gene alleles in the F7 Arg353Gln in the study group were: GG in 30 out of 41 patients $(73.2 \%)$, GA in 11 out of 41 patients $(26.8 \%)$, and none of 41 patients had a polymorphic variant AA. The frequency of alleles of this type of gene in the control group was as follows: GG in 7 out of 320 subjects (2.2\%), GA in 66 out of 320 patients (20.6\%), AA in 247 out of $320(77.2 \%)$. Significant differences were identified in the frequencies of homozygous genotypes, AA $\left(\chi^{2}=100.215, \mathrm{p}<0.001\right)$ and GG $\left(\chi^{2}=205.770, p<0.001\right)$ in the study and control groups respectively. As for the heterozygous GA genotype, the differences were not significant $\left(\chi^{2}=0.834, \mathrm{p}=0.362\right)$. The GG genotype of the gene Val134Leu F13 WAS 2.8 times more frequent in patients of the study group, differences were statistically significant $\left(26.8 \%\right.$ against $\left.9.7 \%, \chi^{2}=10.388 ; p=0.002\right)$. The presence of the TT genotype of the gene Val134Leu F13 was almost five times more frequent $\left(\chi^{2}=18.956, \mathrm{p}<0.001\right)$ in healthy individuals (control group). Differences in the frequency of allele T in homo/ and heterozygous combinations (TT and GT) in the study and control groups was also significant (72.7\% vs $90.1 \%$, respectively, $\chi^{2}=4.946, p=0.027$ ). Discussion Polymorphisms of coagulation factors genes F7 and F13 have a significant effect on the genesis of non-traumatic avascular necrosis of the femoral head. Risk factor of ANFH development is homozygous GG genotype in the gene Arg353Gln F7. Low probability of the disease is due to a protective role of AA genotype of the gene Arg353Gln F7 and TT genotype of the gene Val134Leu F13.
\end{abstract}

Keywords: non-traumatic aseptic necrosis, femoral head, polymorphisms of coagulation factor genes, avascular necrosis, predictors

\section{INTRODUCTION}

Non-traumatic aseptic necrosis of the femoral head (ANFH) is a disease characteristic for males aged 20 to 50 . Disability of young people due to this disease is a socially significant issue $[1,2]$. Long-term use of corticosteroids, alcohol abuse, systemic lupus erythematosus, sickle cell anemia, Legg-Calve-Perthes disease, ionizing radiation, and cytotoxic agents are among the causes of ANFH [3, 4]. However, it is known that necrosis of the femoral head can be observed in the absence of the abovementioned factors - the so-called "idiopathic ANFH".

According to the literature, the development of ANFH is based on three main mechanisms: mechanical obstruction to blood flow, thrombotic occlusion of blood vessels, and extravascular compression [5]. The importance is attributed to the interaction between the genetic predisposition to hemocirculation disorders and external factors. A lot of patients with ANFH feature a combination of unfavorable external risk factors with hereditary ones such as hypercoagulation, hemoglobinopathies, angiogenesis disorders, oxidative stress [6].
It can be assumed that several hereditary features (polymorphisms) of the genes of blood coagulation factors play a certain role in the ANFH pathogenesis. It is known that the hemostasis system is a combination of processes that ensure the liquid state of the blood, maintain its normal viscosity, prevent and stop bleeding. It includes factors of coagulation, natural anticoagulant and fibrinolytic systems of blood. Normally, all the processes are in a certain balance and provide a liquid state of the blood. A shift in the balance due to internal or external factors may increase the risk of bleeding and blood clotting.

In assessing the risk of thromboembolism and heart attacks, special attention is paid to the genes of coagulation (clotting) factors VII and XIII (F7, F13). Their changes are aimed at providing a protective effect in most cases. A decrease in the activity of these factors contributes to a decrease in thrombus formation [7, 8].

The F7 gene encodes coagulation factor VII, a vitamin K-dependent proenzyme produced in the liver. The main physiological role of F7 is the activation of blood coagulation factor X. After damage to the vessel,

[@ Panin M.A., Zagorodnii N.V., Boiko A.V., Samokhodskaya L.M., Abakirov M.D., Volkov E.E. The significance of polymorphisms of gene coagulation factors VII and XIII in the pathogenesis of non-traumatic avascular necrosis of the femoral head. Genij Ortopedii, 2021, vol. 27, no 1, pp. 43-47. DOI 10.18019/1028-4427-2021-27-1-43-47 
F7 binds to tissue factor III and becomes active. This reaction is the main event in the process of blood clotting [9]. Changes in the F7 gene have a protective effect on the risk of thromboembolism in most cases. Substitution of guanine $(\mathrm{G})$ for adenine (A) at position 10976 (genetic marker G10976A) leads to a change in the biochemical properties of factor VII. The decrease in F7 activity as a result of replacement helps to reduce thrombus formation. The AA genotype is a cause for a 72 $\%$ decrease in the activity of the F7 enzyme as compared to the wild one (most often found in the population), the GG genotype [10]. The marker is associated with a decrease in the likelihood of myocardial infarction, even if severe coronary atherosclerosis has been angiographically documented. Heterozygotes (carriers of one allele $A$ and one $\mathrm{G}$, genotype $\mathrm{AG}$ ) have a risk of myocardial infarction two times less than carriers of two alleles G (genotype GG) [11].

Factor XIII (F13) is a plasma glycoprotein that circulates in the blood plasma in combination with the fibrinogen protein. When the blood coagulation system is activated, F13 is degraded by the enzyme thrombin (coagulation factor II). Calcium ions are a cofactor in this reaction. The activated protein $\mathrm{F} 13 \mathrm{a}$ catalyzes the "crosslinking" of fibrin monomers, forming bonds between amino acids, what leads to the formation of fibrin polymer. Fibrin is the basis of a blood clot; it stabilizes a thrombus, completing the process of blood coagulation [12]. Changes in the F13 gene in most cases reduce the risk of developing pathologies associated with increased thrombus formation. The site where the guanine $(G)$ nucleotide is replaced by thymine $(\mathrm{T})$ at position 103 is designated as the genetic marker G103T. The biochemical properties of the F13 protein are transformed due to the substitution, and namely, its ability to "crosslink" fibrin monomers, as a result of which fibrin clots become thinner [13]. When analyzing the frequency of alleles (G103T) in patients with myocardial infarction and in the control group, the protective effect of the $\mathrm{T}$ allele presence in the genotype was proven [14].

The aim of this research was to study the contribution of polymorphisms of the coagulation factors genes F7 and F13 in the genesis of nontraumatic aseptic necrosis of the femoral head.

\section{MATERIAL AND METHODS}

The research was based on the assumption about an important role of genetic factors in the development of aseptic necrosis of the femoral head. Therefore, we studied the polymorphism of the blood coagulation genes F7 and F13. Their role in the genesis of various ischemic disorders has been known.

In the course of the comparative study, the frequency of significant allelic variants of genes F7 (Arg353Gln) and F13 (Val134Leu) in patients with a verified diagnosis of ANFH (study group) and in healthy patients (control group) was analyzed.

We examined 41 patients (all males) with ANFH. This group included patients with an unclear cause of the disease, clinically manifested at the age of 27 to 45 years. Exclusion criteria were alcoholism, longterm use of corticosteroids, systemic connective tissue diseases, blood diseases, and other known etiological factors of ANFH [15].

The duration of the disease varied from 1 to 20 years. At the time of examination, 24 out of 41 patients of the study group underwent one- or two-sided total hip arthroplasty one 1 to 10 years ago due to secondary arthrosis caused by ANFH in grade 3-4. Fifteen patients with ANFH in grade 3 were preparing for a similar operation. Two patients (ANFH grade 3) received conservative treatment as they rejected the arthroplasty. The family history of patients with ANFH revealed a high incidence of cardiovascular diseases (stroke, heart attack, acute thrombosis) in the close relatives (mother / father) in $61 \%$ ( 25 out of 41 ) of patients in the study group. It should be emphasized that both parents in 13 patients had cardiovascular diseases, and six of them with a fatal outcome.

Examination of the somatic status detected arterial hypertension of grade 1-3 in 12 patients of the study group, six cases of varicose veins of the lower extremities, three had a history of acute thrombophlebitis, requiring surgical intervention, and three patients had coagulopathy (hyperfibrinogenemia) requiring permanent medication correction. The control group included 320 men of the same age group (25-45 years old), a military personnel studied during routine examinations [16]. None of the patients in the control group had clinical manifestations of hip joint diseases.

The examination program included the study of polymorphisms of the Arg353Gln F7 and Val134Leu F13 genes by the PCR method. For genetic research, genomic DNA was extracted on a sorbent from lymphocytes of peripheral whole blood using a commercial kit "DNA-sorb-B" (AmpliSens, Moscow).

Allelic variants of the genes were determined by real-time PCR on a DT-96 amplifier (DNA Technology, Russia) with test systems for PCR analysis (DNA Technology, Russia) according to the manufacturer's recommendations.

Statistical processing of the data obtained for comparison was performed between the results in the study and control groups. The reliability of 
the values was determined with the STATISTIKA calculating the $\mathrm{p}$-value using the Pearson $\chi^{2}$ test. All individuals included in the study gave written informed consent to participate in it. The study was approved by the Ethics Committee of the RUDN University.

\section{RESULTS}

We analyzed the frequencies of the $\mathrm{A}$ and $\mathrm{G}$ alleles (in homo- and heterozygous state) of the Arg353Gln F7 gene in ANFH patients and in healthy people. Table 1 shows that the allele A was detected in $26.8 \%$ of patients of the study group, which is 3.5 times lower than in the control group (97.1\%); the differences are statistically significant. Allele $\mathrm{G}$ in the genotype was noted in $73.2 \%$ of patients with ANFH and in $22.8 \%$ of individuals from the control group; the differences are also statistically significant (Table 1).

Table 1

Alleles A and G of the Arg353Gln F7 gene in patients of two groups

\begin{tabular}{|l|c|c|c|c|}
\hline & $\begin{array}{c}\text { Study group } \\
(\mathrm{ANFH}, \mathrm{n}=41)\end{array}$ & $\begin{array}{c}\text { Control group } \\
(\mathrm{n}=320)\end{array}$ & $\chi^{2}$ & $\mathrm{p}$ \\
\hline $\begin{array}{l}\text { Allele A } \\
\text { (genotypes } \\
\text { AA+GA) }\end{array}$ & $11 / 41-26.8 \%$ & $311 / 320-97.1 \%$ & 186.703 & $<0.001$ \\
\hline $\begin{array}{l}\text { Allele G } \\
\text { (genotypes } \\
\text { GG+GA) }\end{array}$ & $30 / 41-73.2 \%$ & $73 / 320-22.8 \%$ & 45.199 & $<0.001$ \\
\hline
\end{tabular}

The frequency of alleles of the Arg353Gln F7 gene in the study group was: GG in 30 out of 41 patients $(73.2 \%), \mathrm{GA}$ - in 11 out of 41 (26.8\%), and the polymorphic AA variant was not found in any of 41 patients. In the control group, the allele frequencies of this gene were distributed as follows: $\mathrm{GG}-$ in 7 out of 320 individuals (2.2) \%, GA - in 66 out of 320 (20.6\%), AA - in 247 out of $320(77.2 \%)$.

We found significant differences in the frequencies of homozygous genotypes, AA $\left(\chi^{2}=100.215\right.$, $\mathrm{p}<0.001)$ and GG $\left(\chi^{2}=205.770, \mathrm{p}<0.001\right)$ in the study and control groups (Fig. 1). In relation to the heterozygous GA genotype, the differences were not significant $-\chi^{2}=0.834, p=0.362$.

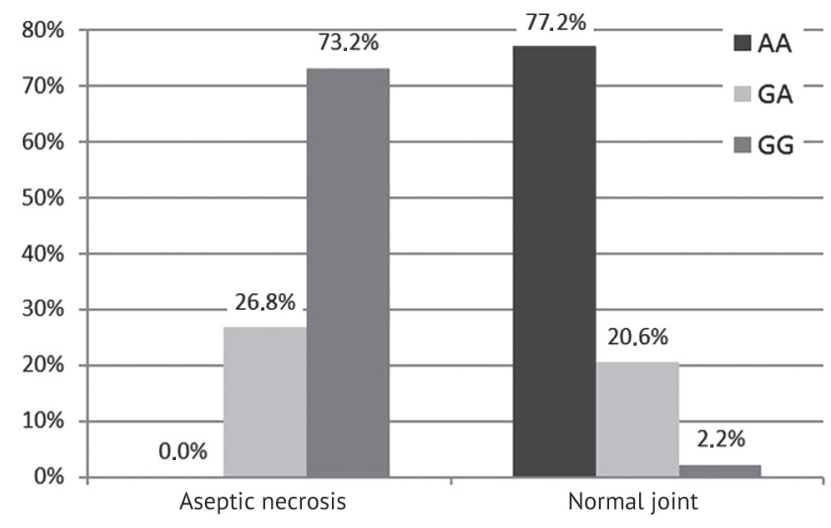

Fig. 1 Frequency of alleles of the Arg353Gln F7 gene in patients with ANFH and in the control group

Subsequently, we analyzed the frequencies of various allelic variants of the Val134Leu F13 gene. The frequency of $\mathrm{T}$ allele detection (TT $+\mathrm{TG}$ genotypes) in ANFH patients was $73.2 \%$, in the control group $90.0 \%$; the differences are statistically significant $(p=0.002)$. The differences in the frequency of the $G$ allele were even more significant, $90.2 \%$ in the study group and $54.7 \%$ in the control group; the differences are statistically significant, $\mathrm{p}<0.001$ (Table 2 ).

Table 2

Presence of T and G alleles of the Val134Leu F13 gene in patients of two groups

\begin{tabular}{|l|c|c|c|c|}
\hline & $\begin{array}{c}\text { Study group } \\
(\mathrm{ANFH}, \mathrm{n}=41)\end{array}$ & $\begin{array}{c}\text { Control group } \\
(\mathrm{n}=320)\end{array}$ & $\chi^{2}$ & $\mathrm{p}$ \\
\hline $\begin{array}{l}\text { Allele A } \\
\text { (genotypes } \\
\text { AA+GA) }\end{array}$ & $30 / 41-73.2 \%$ & $288 / 320-90.0 \%$ & 9.810 & 0.002 \\
\hline $\begin{array}{l}\text { Allele G } \\
\text { (genotypes } \\
\text { GG+GA) }\end{array}$ & $37 / 41-90.2 \%$ & $175 / 320-54.7 \%$ & 18.956 & $<0.001$ \\
\hline
\end{tabular}

Analysis of the frequency of various allelic variants of the Val134Leu F13 gene showed that the presence of homozygous TT genotype was noted in 4 out of 41 patients $(9.8 \%)$ of the study group, heterozygous GT genotype in 26 out of $41(63.4 \%)$, homozygous GG genotype in 11 out of 41 (26.8\%). In the control group, the frequency of these genotypes was, respectively, $45.3 \%$ (145 out of 320$), 45.0 \%$ (144 out of 320$)$ and $9.7 \%$ (31 out of 320) (Fig. 2).

The GG genotype was 2.8 times more common in patients of the study group; the differences are statistically significant $(26.8 \%$ versus $9.7 \%$, $\left.\chi^{2}=10.388, \mathrm{p}=0.002\right)$.

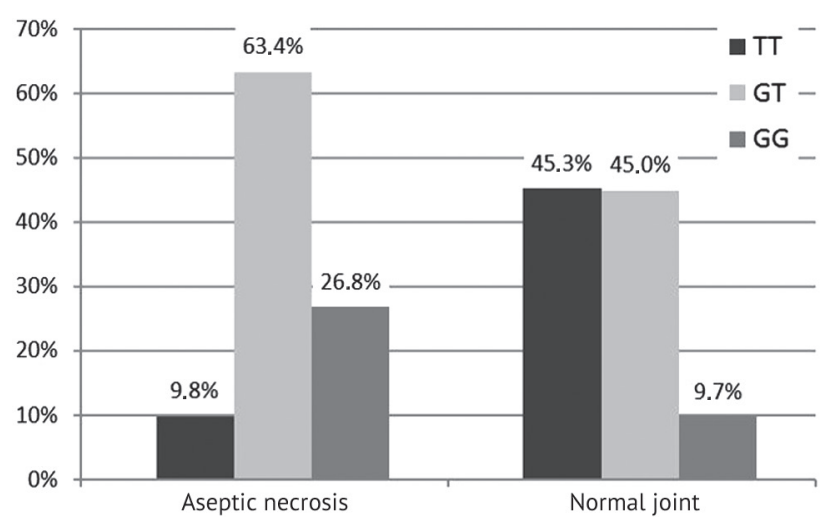

Fig. 2 Frequency of allele variants of gene Val134Leu F13 in patients of both groups

Taking into account the literature data on the protective role of the $\mathrm{T}$ allele in the development of ischemic disorders, we analyzed the frequency of this allele in the studied groups.

The presence of the TT genotype of the Val134Leu F13 gene was almost 5 times more likely $\left(\chi^{2}=18.956\right.$, 
$\mathrm{p}<0.001$ ) in healthy people (control group). Differences in the frequency of $\mathrm{T}$ allele in homo- and heterozygous combinations (TT and GT) in the study and control groups were also statistically significant $\left(72.7 \%\right.$ versus $90.1 \%$, respectively, $\chi^{2}=4.946$, $\mathrm{p}=0.027)$. Taking into account the difference in the reliability $(p<0.001$ versus $p=0.027)$, it can be concluded that the key protective role against the development of aseptic necrosis of the femoral head is played only by the homozygous TT genotype.

\section{DISCUSSION}

Our study has established the possible causes of the so-called idiopathic necrosis of the femoral head. It was shown that the risk of developing ANFH is increased with certain polymorphisms of the coagulation factors F7 and F13 genes.

Our data suggest that the presence of the $G$ allele of Arg353Gln F7 gene can be considered as one of the risk factors in the development of aseptic necrosis of the femoral head. The frequency of the homozygous GG genotype of Arg353Gln F7 gene in patients with aseptic necrosis of the femoral head, which was more than 30 times higher compared to the control group, might indicate the high significance of blood coagulation disorders in the genesis of this disease.

The universal nature of ischemic disorders in the human body was shown by the results of a study by M. Ramzia et al., who revealed a twofold increase in the risk of myocardial infarction in the carriers of the homozygous GG allele of the Arg353Gln F7 gene [17].

Also, we found that the allele A of the Arg $353 \mathrm{Gln}$ F7 gene was 3.5 times more frequent in the control group. This indicates its protective role in relation to the development of ANFH. It is known that the AA genotype is the cause of a $72 \%$ decrease in the F7 enzyme activity and is associated with a decrease in the likelihood of myocardial infarction even in the presence of severe coronary atherosclerosis [10]. In relation to the AA genotype of the Arg353Gln F7 gene, it is important to note that it was not detected by us in any of the patients of the study group. There are literature reports on the protective role of this allele in relation to myocardial infarction and ischemic stroke [11], which indicates similar elements of the pathogenesis of "major vascular catastrophes" and ANFH.

When analyzing the polymorphisms of Val134Leu F13 gene, we found that the GG allelic polymorphism can be considered as one of the risk factors for ANFH. The frequencies of this polymorphism were significantly different in the study and control groups $\left(\chi^{2}=10.388, p=0.002\right)$. We found no literature data indicating an unfavorable prognostic role of the GG genotype of the Val134Leu F13 gene in the genesis of ischemic disorders.

The TT genotype of the Val134Leu F13 gene was almost five times more common in healthy people than in patients with ANFH. Differences in the frequency of the $\mathrm{T}$ allele in homo- and heterozygous combinations (TT and GT) in the study and control groups were also statistically significant $(72.7 \%$ versus $90.1 \%$, respectively, $\left.\chi^{2}=4.946, \mathrm{p}=0.027\right)$. Taking into account the difference in reliability $(p<0.001$ versus $p=0.027$ ), it can be concluded that the homozygous TT genotype plays a key protective role against the development of aseptic necrosis of the femoral head. Low frequency of the T allele of the Val134Leu F13 gene in the group of patients with myocardial infarction compared with the control group was shown by Kreutz R. et al. [18], that confirms the "coagulopathic" genesis of the so-called idiopathic necrosis of the femoral head.

The homozygous GG genotype of the Val134Leu F13 gene was 2.8 times more frequent in patients with ANFH (26.8 \% in the study group versus $9.7 \%$ in the control group, $\mathrm{p}=0.002$ ). There are variations in the interpreting the obtained data. Due to a relatively low (less than one third) frequency of the GG genotype in the study group, it is difficult to assert that the GG genotype is an independent risk factor for ANFH. Probably, it is not the presence of the GG genotype that matters, but the absence of the $\mathrm{T}$ allele in the genotype.

\section{CONCLUSIONS}

Our study shows that the polymorphisms of coagulation factors $\mathrm{F} 7$ and $\mathrm{F} 13$ genes have a significant effect on the genesis of non-traumatic avascular necrosis of the femoral head. Risk factor of ANFH development is homozygous GG genotype in the gene Arg353Gln F7. Low probability of the disease is due to a protective role of AA genotype of the gene Arg $353 \mathrm{Gln}$ F7 and TT genotype of the gene Val134Leu F13.

The authors declare that they have no conflicts of interest.

There was no external funding. 


\section{REFERENCES}

1. Shannon B.D., Trousdale R.T. Femoral osteotomies for avascular necrosis of the femoral head. Clin. Orthop. Relat. Res., 2004 , no. 418, pp. 34-40. DOI: 10.1097/00003086-200401000-00007.

2. DeSmet A.A., Dalinka M.K., Alazraki N.P., Daffner R.H., El-Khoury G.Y., Kneeland J.B. et al. Expert Panel on Musculoskeletal Imaging. Avascular necrosis of the hip. American College of Radiology (ACR), Reston (VA), 2005. URL: http://www.guidelines. gov/summary/summary.aspx? doc_id=8296\&nbr $=004628 \&$ string $=$ avascular + AND + necrosis.

3. Mont M.A., Marulanda G.A., Jones L.C., Saleh K.J., Gordon N., Hungerford D.S., Steinberg M.E. Systematic analysis of classification systems for osteonecrosis of the femoral head. J. Bone Joint Surg. Am., 2006, vol. 88, no. 3, pp. 16-26. DOI: 10.2106/ JBJS.F.00457.

4. Panin M.A., Zagorodnii N.V., Karchebnyi N.N., Sadkov I.A., Petrosian A.S., Zakirova A.R. Sovremennyi vzgliad na patogenez netravmaticheskogo osteonekroza [Modern view of the pathogenesis of non-traumatic osteonecrosis]. Vestnik Travmatologii $i$ Ortopedii imeni N.N. Priorova [Priorov Bulletin of Traumatology and Orthopaedics], 2017, no. 2, pp. 69-75. (in Russian).

5. Jones L.C., Mont M.A., Le T.B., Petri M., Hungerford D.S., Wang P., Glueck C.J. Procoagulants and osteonecrosis. J. Rheumatol., 2003, vol. 30, no. 4, pp. 783-791.

6. Glueck C.J., Freiberg R.A., Oghene J., Fontaine R.N., Wang P. Association between the T-786C eNOS polymorphism and idiopathic osteonecrosis of the head of the femur. J. Bone Joint Surg. Am., 2007, vol. 89, no. 11, pp. 2460-2468. DOI: 10.2106/JBJS.F.01421.

7. Di Minno G., Grandone E., Margaglione M. Clinical relevance of polymorphic markers of arterial thrombosis. Thromb. Haemost., 1997, vol. 78, no. 1, pp. 462-466.

8. Grant P.J. Polymorphisms of coagulation/fibrinolysis genes: gene environment interactions and vascular risk. Prostaglandins Leukot. Essent. Fatty Acids., 1997, vol. 57, no. 4-5, pp. 473-477. DOI: 10.1016/s0952-3278(97)90431-2.

9. Kuznik B.I. Sistema gemostaza [Hemostasis System]. Fiziologiia Cheloveka, 2000, no. 1, pp. 313-325. (in Russian)

10.Golino P. The inhibitors of the tissue factor: factor VII pathway. Thromb. Res., 2002, vol. 106, no. 3, pp. V257-V265. DOI: 10.1016/ s0049-3848(02)00079-8.

11.Kang W.Y., Wang H.L., Xiong L.F., Wang X.F., Chu H.Y., Qu B., Liu X.F., Yin J., Duan B.H., Wang Z.Y. Polymorphisms of the coagulation factor VII gene and its plasma levels in relation to acute cerebral infarction differences in allelic frequencies between Chinese Han and European populations. Chin. Med. J. (Engl), 2004, vol. 117, no. 1, pp. 71-74.

12.Komáromi I., Bagoly Z., Muszbek L. Factor XIII: novel structural and functional aspects. J. Thromb. Haemost., 2011, vol. 9, no. 1, pp. 9-20. DOI: 10.1111/j.1538-7836.2010.04070.x.

13.Muszbek L., Ariëns R.A., Ichinose A. ISTH SSC Subcommittee on Factor XIII. Factor XIII: recommended terms and abbreviation. J. Thromb. Haemost., 2007, vol. 5, no. 1, pp. 181-183. DOI: 10.1111/j.1538-7836.2006.02182.x.

14.Bronić A., Ferencak G., Zadro R., Stavljenić-Rukavina A., Bernat R. Impact of FXIII-A Val34Leu polymorphism on coronary artery disease in Croatian patients. Mol. Biol. Rep., 2009, vol. 36, no. 1, pp. 1-5. DOI: 10.1007/s11033-007-9144-9.

15.Narayanan A., Khanchandani P., Borkar R.M., Ambati C.R., Roy A., Han X., Bhoskar R.N., Ragampeta S., Gannon F., Mysorekar V., Karanam B., Sai Muthukumar V., Sivaramakrishnan V. Avascular Necrosis of Femoral Head: A Metabolomic, Biophysical, Biochemical, Electron Microscopic and Histopathological Characterization. Sci. Rep., 2017, vol. 7, no. 1, pp. 10721. DOI: 10.1038/ s41598-017-10817-w.

16.Andreenko E.Iu., Samokhodskaia L.M., Balatskii A.V., Makarevich P.I., Boitsov S.A. Prognosticheskaia znachimost nositelstva allelnykh variantov genov, kontroliruiushchikh sistemu gemostaza, i ikh sochetaniia s traditsionnymi faktorami riska $\mathrm{v}$ rannem razvitii ishemicheskoi bolezni serdtsa [The prognostic significance of the carriage of allelic variants of genes that control the hemostasis system, and their combination with traditional risk factors in the early development of ischemic heart disease]. Kardiovaskuliarnaia Terapiia i Profilaktika, 2011, vol. 10, no. 8, pp. 32-39. (in Russian)

17.Ramzi M., Cohan N., Yavarian M., Jahromi M.R. Coagulation factor VII gene polymorphisms and cardiovascular diseases in Iranian population. J. Indian College of Cardiology, 2013, vol. 3, no. 1, pp. 6-8. DOI: 10.1016/j.jicc.2012.12.004.

18.Kreutz R.P., Bitar A., Owens J., Desta Z., Breall J.A., Von der Lohe E., Sinha A., Vatta M., Nystrom P., Jin Y., Flockhart D.A. Factor XIII Val34Leu polymorphism and recurrent myocardial infarction in patients with coronary artery disease. J. Thromb. Thrombolysis, 2014, vol. 38, no. 3, pp. 380-387. DOI: 10.1007/s11239-014-1059-4.

Received: 27.01.2020

\section{Information about the authors:}

1. Mikhail A. Panin, M.D., Ph.D., RUDN University, Moscow, Russian Federation

2. Nikolai V. Zagorodnii, M.D., Ph.D., Professor, corresponding member of RAMS, RUDN University, Moscow, Russian Federation

3. Andrei V. Boiko,

RUDN University, Moscow, Russian Federation,

Email: boiko120393@gmail.com

4. Larisa M. Samokhodskaya, M.D., Ph.D.,

Lomonosov Moscow State University, Moscow, Russian Federation

5. Medetbek Dz. Abakirov, M.D., Ph.D.,

RUDN University, Moscow, Russian Federation

6. Evgeny E. Volkov, M.D., Ph.D.,

Specialized Center for the Treatment of Aseptic Necrosis, Moscow, Russian Federation,

Email: volkov@femurhead.ru 